Case Report

\title{
Return to cycling after hip arthroplasty: a case report of femoroacetabular impingement
}

\author{
Rayane Anhalt ${ }^{1}$, Rose Löbell ${ }^{1}$, Felipe P Fagundes ${ }^{1}$ and Michele F Saccol ${ }^{1, *}$ \\ 1 Laboratório de Biomecânica - Universidade Federal de Santa Maria, Brazil
}

* Correspondence: Michele Forgiarini Saccol. mfsaccol@gmail.com

Received: 18 December 2021; Accepted: 31 May 2021; Published: 30 June 2021

\begin{abstract}
This study aims to describe the pre and postoperative functional deficits of a recreational cycling athlete diagnosed with severe femoroacetabular impingement. Assessments were performed before, and at 8 and 24 months after total hip arthroplasty using patient reported outcome measures and strength assessment. The participant presented a progressive improvement in postoperative assessment regarding pain and function according to the Western Ontario and McMaster Universities Osteoarthritis Index and the Lower Extremity Functional Scale. There was a reduction in the time to perform the Time Up and Go Test and an improvement of strength deficits, especially in abductors (deficit from $64.8 \%$ to $6.5 \%$ in the pre versus post 24 months) and hip adductors (deficit from $30 \%$ to $15,7 \%$ in the pre versus post 24 months). The return to cycling occurred gradually after surgery, showing the efficacy and good responsiveness to treatment.
\end{abstract}

Keywords: femoracetabular impingement; osteoarthritis; hip.

\section{Introduction}

Femoroacetabular impingement (FAI) is a condition of signs and symptoms caused by changes in the morphology of the femoral head or neck. The abnormal contact between these structures with the acetabulum is the cause of pain during hip flexion, especially in the extreme degrees of movement, which directly reflects in the reduction of functionality (Griffin et al., 2016).

FAI is one of the main causes of hip pain in sports practitioners, especially those who perform flexion, adduction, and internal rotation of the hip concurrently (Frank et al., 2018; Griffin et al., 2016). Modalities such as cycling require the performance of these movements cyclically and repeatedly (Frank et al., 2018).

Conservative treatment is recommended as the initial approach to
FAI, but in advanced stages, when there is already degeneration of the joint capsule, surgical treatment is indicated (Griffin et al., 2016) Resumption of function and return to sport should be a priority in the postoperative (PO) period (Frank et al., 2018). Also, it is important to assess functional asymmetries for a safe return to sports, which possibly remain even after a considerable PO period (Diamond et al., 2015).

The present case report is about an amateur cyclist with an advanced stage of FAI with characteristics of severe osteoarthritis (OA). The aim of this report is to describe the main pre and postoperative functional deficits of this patient, monitoring how these aspects change over time until he returns to cycling.

\section{Materials and Methods}

() 2021 fist author, licensee JSC. This is an Open Access article distributed under the terms of the Creative Commons Attribution License ((http://creativecommons.org/licenses/by/4.0/) which permits unrestricted use, distribution, and reproduction in any medium, provided the original work is properly cited. 
The present case report was approved by the ethics committee from the Federal University of Santa Maria (CAAE: 81112317.9.0000.5346). A 47-year-old man, technology analyst and amateur cyclist, diagnosed with bilateral FAI in 2003 (mild degree in the left hip and severe degree in the right hip).

In 2018, due to the evolution of OA in the right hip, cementless total hip arthroplasty (THA) was performed with a ceramic prosthesis and posterior surgical approach. The patient had not undergone previous surgery or preoperative physiotherapy. Physical and functional evaluations were performed five days before surgery (PRE) and were repeated at 8 (PO8) and 24 (PO24) months after surgery $(\mathrm{PO})$.

The patient had a height of $1.82 \mathrm{~m}, 85.8$ $\mathrm{kg}$ of body mass in the PRE evaluation (Body Mass Index-BMI $25.9 \mathrm{~kg} / \mathrm{m} 2$ ), 82.4 $\mathrm{kg}$ in the PO8 evaluation (BMI $24.88 \mathrm{~kg} /$ $\mathrm{m} 2$ ), and $80.5 \mathrm{~kg}$ in PO24 evaluation (BMI $24.3 \mathrm{~kg} / \mathrm{m} 2)$, indicating overweight in PRE evaluation and normal weight in PO1 and $\mathrm{PO} 2$ evaluations.

Function was assessed using selfreport instruments validated in the literature: the Western Ontario and McMaster Universities Osteoarthritis Index (WOMAC) (Quintana et al., 2005) and the Lower Extremity Functional Scale (LEFS)(Dingemans et al., 2017). The WOMAC is an instrument widely used for OA assessment with three specific sessions: pain, joint stiffness and function, with higher scores indicating a patient's greater clinical impairment (Quintana et al., 2005). The LEFS is a general questionnaire for functionality of lower limbs with a score ranging from 0 to 80 , with higher scores indicating lower functional impairments (Dingemans et al., 2017).

The dynamic balance function was assessed by the Timed Up and Go test. In this test, the individual is instructed to get up from a chair, walk a distance of 3 meters, turn around, return on the same route and sit on the chair. The individual is instructed to perform the task safely and as quickly as possible, and his performance is quantified by measuring the time required to perform it (Greene et al., 2010).

The evaluation of muscle strength was performed with a hand-held dynamometer (Microfet 2, Hoogan Health industries) for muscle groups related to the hip joint of both lower limbs (abductors, adductors, flexors, and extensors) (K. Thorborg et al., 2010a). The patient performed a muscular contraction against the resistance in an isometric way for a period of 5 seconds in 3 valid attempts, accepting a variability of the measures of $\pm 10 \%$ (figure 1 ). For strength analysis, it was considered the average of the valid measures of each evaluation. The percentage difference was used to compare the performance in the three assessments and the deficit between the affected and non-affected members, graduated in light imbalance (11\% $-20 \%)$, mild imbalance $(21-30 \%)$, moderate $(31 \%$ $-40 \%)$, accentuated $(41 \%-50 \%)$ and severe (51\% $-60 \%)$ (Perrin, 1993).

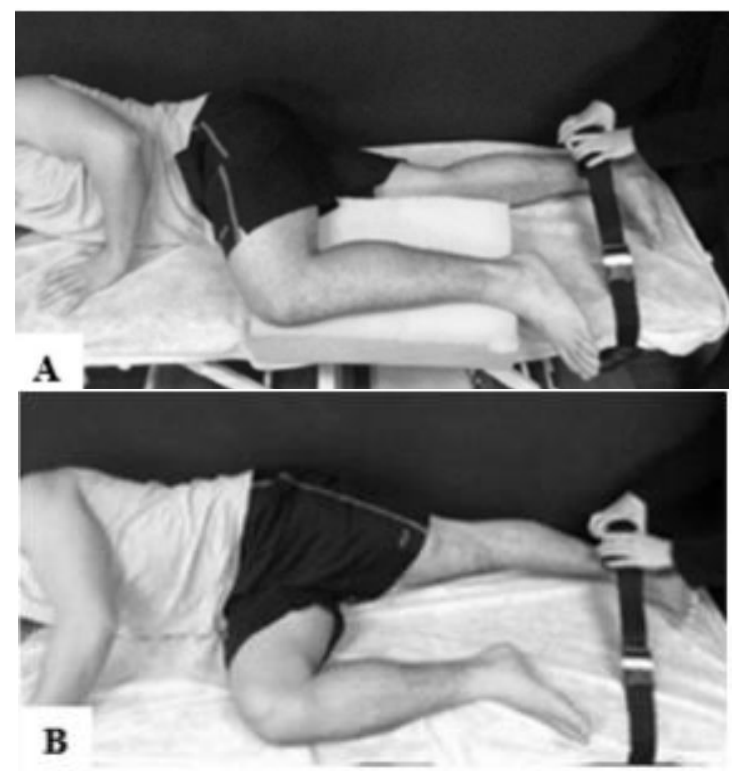

Figure 1 - Positioning assessment for isometric adductors (A) and abductors (B) hip strength.

According to the patient's description, the hospital stays lasted 3 days, with 
partial unloading weight on the operated limb on the first day after surgery and use of crutches for 20 days. The patient underwent physical therapy in the PO period during hospitalization and maintained a follow-up routine at home with a physiotherapist for two months after the surgery.

Before surgery, patient activity selfreport revels a regular practice of weight training and cycling with a frequency of six times per week (alternating modalities) and with a cycling volume of approximately $100 \mathrm{~km}$ per week. Despite being able to perform these activities in the preoperative period, the reported pain scored 5 on a visual analog scale (VAS: 010, with 0 corresponding to no pain and 10 representing the worst possible pain).

The return to weight training occurred after the first month PO, with adaptations in the execution of the exercises and a frequency of 2 times per week. While cycling was resumed at 4 months $\mathrm{PO}$, with a frequency of 2 to 3 times per week and an average volume of 46.8 $\mathrm{km} /$ week. At PO24, weight training was continued twice a week and cycling training three times per week, with an average volume of $60 \mathrm{~km}$ per week, with no reports of pain.

\section{Results}

Table 1 shows the comparison of the results between the assessments. There was a good clinical response of pain, stiffness, and functions, which shows improvement in both postoperative evaluations: PO8 (approximately 40\%) and PO24 (approximately 90.8\%), according to the WOMAC score. The general function of the lower limb measured by the LEFS also showed an increasing improvement in the period, as well as a reduction in the time for the execution of the TUG in both reevaluations, with a shorter execution time (PRE), at 8 (PO8) and 24 months (PO24) after total hip arthroplasty.

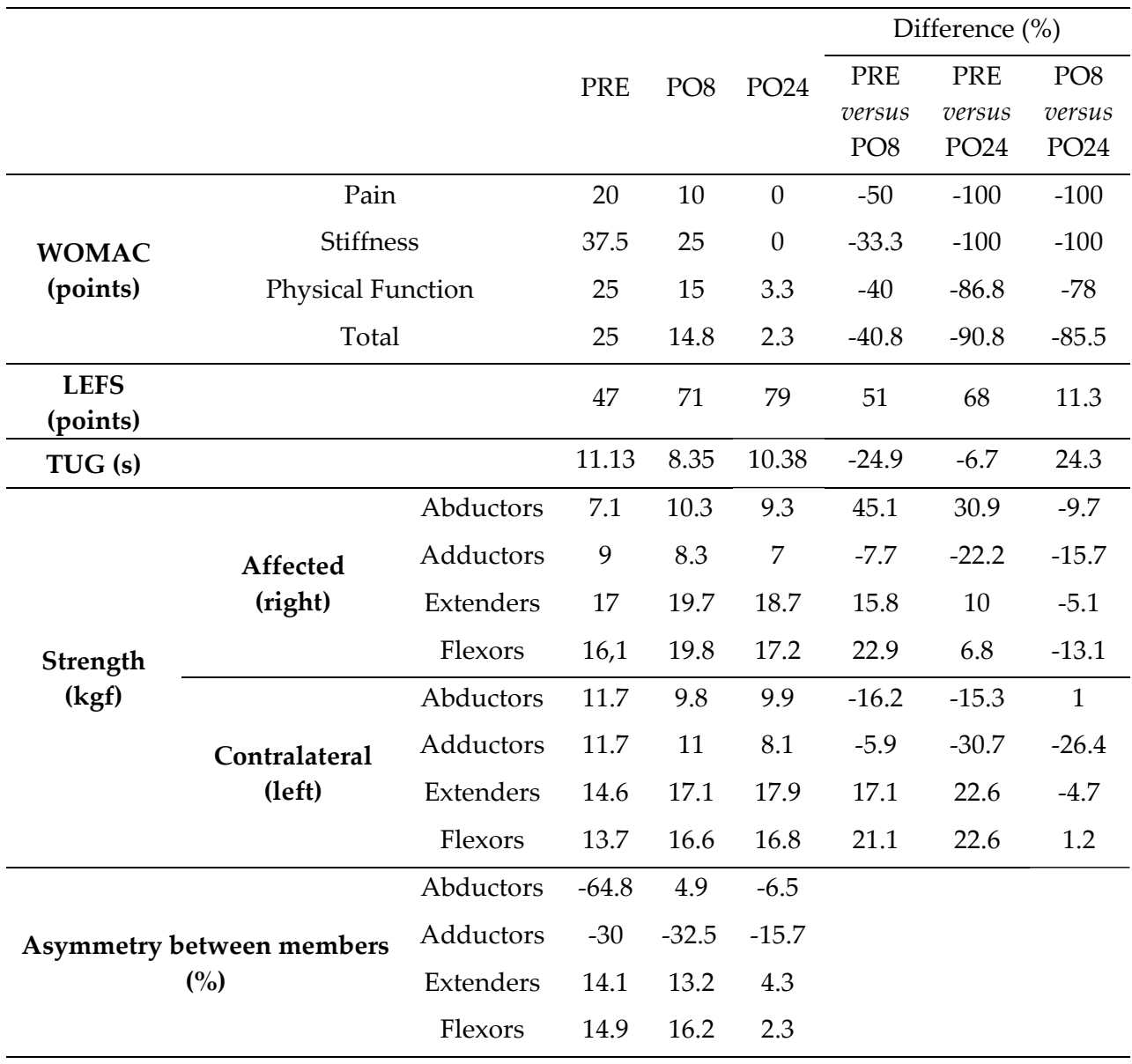

observed in the PO8.

The resolution of asymmetries in the evaluated muscle groups was generally observed, with a slight deficit of adductor strength $(15.7 \%)$ and hip flexors (13.1\%) remaining at $\mathrm{PO} 24$ when compared to the pre-surgery evaluation. 
There was a good clinical evolution in the hip abductors' asymmetry, with a deficit between limbs of $-64.8 \%$ (PRE), reducing to $4.9 \%$ (PO8) and $-6.5 \%$ (PO24). The same was observed in the adductors' asymmetry, where there was a reduction of $-30 \%$ (PRE) in asymmetry to $-15.7 \%$ (PO24).

\section{Discussion}

Our objective was to describe the evolution of physical and functional aspects of an amateur cyclist who underwent THA surgery due to severe FAI in the right hip, assessed before and after surgery. These data are important for patients and professionals to understand what to expect after hip arthroplasty, especially in recreational athletes who participate in potentially high-risk activities, such as cycling. Studies have consistently shown a median satisfaction of pain relief and substantial improvement in function and quality of life after THA (Jones \& Pohar, 2012; Montin et al., 2011). Corroborating with this, we noticed an improvement in strength and function throughout the evaluations. The changes in asymmetries verified between PO8, and PO24, occurred especially in PO8 for hip abductors and in $\mathrm{PO} 24$ for adductors, indicating a tendency towards normalization over time.

After THA, pain and stiffness gradually decreased, reaching the absence of symptoms in the $\mathrm{PO} 24$, when the changes in the scores reached the minimum clinical differences (MCD) for all domains of the WOMAC questionnaire (Quintana et al., 2005). At PO8, pain reduced by 20 points $(\mathrm{MCD}=21.38)$; rigidity by 37.5 points $(\mathrm{MCD}=27.98)$ and functionality limitations reduced by 21.7 points $(\mathrm{MCD}=11.93)$ (Quintana et al., 2005). About LEFS, values higher than the recommended in the MCD (9 points) (Mehta et al., 2016) were observed in the two re-evaluations. These results point to an improvement of function over time since the higher scores in those scales indicate lower functional impairments.
This improvement in the function and clinical aspects of FAI demonstrated a good physical response to THA. Thus, it is understandable that the return to the practice of weightlifting occurred one month after surgery and the return to cycling at 4 months PO. The good physical and functional conditions assessed at $\mathrm{PO} 8$ may also be related to this early resumption of physical activity and were evident in TUG performance as well, since 1.62 second reduction is already considered a clinically relevant change in subjects after THA(Yuksel et al., 2021).

The overall rate of return to cycling after hip arthroscopy is $97 \%$, with $41 \%$ of subjects returning to the same level of performance and another $59 \%$ achieving a performance even higher than preoperative levels (Diamond et al., 2015). This high rates of return to sport after surgery may be explained by the nonweight bearing and smooth action in cycling (So et al., 2005) associated with the constrained reciprocal limb extension and flexion phases of a repeatable kinematic movement (Lai et al., 2020).

During the cycling task, proximal muscles at the hip and knee produce the majority of positive work to propel the rider and bicycle forward (Martin \& Brown, 2009; Martin \& Nichols, 2018) The hip and knee flexors and extensors act in a coordinated pattern producing energy to propel the crank (Raasch \& Zajac, 1999; So et al., 2005), while other muscles of thigh and leg acts to maximize energy transfer from the cyclist to the bike (Raasch \& Zajac, 1999). Considering that the muscles which provide most of the power are knee and hip extensors (Ryan \& Gregor, 1992), it's not surprising that only light imbalances between members were evident for hip flexors and extensors at PRE and PO8, since the patient did not interrupt regular practice of weight training and cycling previous to surgery. Ergometer cycling and maximal strength training are even recommended in the early postoperative phase of THA (di Monaco \& Castiglioni, 2013; Liebs et al., 2010), since they are effective ways of 
achieving significant and clinically important improvement in health-related quality of life and satisfaction for patients after surgery (Liebs et al., 2010).

Even with knee and hip providing most of the joint moment power, a muscle coordination at the hip, knee and ankle is needed to transfer the mechanical energy between joints (So et al., 2005). This optimized muscle activation may be threatened if particular muscles become too strong or too weak and development of muscle balance are necessary when muscle training and rehabilitation programs are designed (So et al., 2005). In this case report, strength deficits were evident in the pre surgery phase and decreased over time, remaining in acceptable deficits (no differences to light imbalances between limbs).

Higher deficits in hip abductors and adductors strength were observed in the pre surgery assessment. It is known that hip OA progress aggravates muscle weakness and reduce muscle volume (Loureiro et al., 2018; Zacharias et al., 2016), which explains this pre surgery deficits. At PO8, strength gains were more evident confirming that improved functionality and early return to strength training and cycling may have reduced residual deficits throughout the assessments(Friesenbichler et al., 2017). Therefore, we recommend that after pain resolution and with progressive range of motion gains, athletes should undergo a progressive resistance training aiming to restore symmetry of strength between the lower limbs.

The severe asymmetry in hip abductors strength was remedied after surgery, with no differences between limbs detected at PO8. This high deficit in hip abductors pre-operative may be related to OA hip muscle weakness and joint pain. With the THA and absence of hip pain, post surgery strength gains are expected especially in the first PO month (Friesenbichler et al., 2017), as occurred in our study. Furthermore, post-surgery strength gains are related to individual factors such as age, male gender, regular BMI, and being physically active in the preoperative period (Winther et al., 2019), factors that are strongly correlated to the return to sports (Williams et al., 2012) and present in our patient.

Patients with symptomatic FAI presented muscle weakness for all hip muscle groups, except for internal rotators and extensors (Casartelli et al., 2011). Also, persons with unilateral hip OA have generalized muscle weakness and muscle atrophy in the affected leg (Loureiro et al., 2013). So, it is expected that the presence of mild contralateral hip OA besides FAI and THA may have contributed to strength imbalances in hip abductors and adductors, which may also explain the contralateral limb strength decrease of these muscles at PO24. Interventions to retain bilateral muscle strength during early-middle stages of hip OA are warranted in the conservative management of this condition (Loureiro et al., 2018). However, mechanisms underlying muscle weakness are multifactorial and include reduced muscle size (atrophy), muscle inhibition, and decreased muscle quality (Loureiro et al., 2013), factors that must be addressed therapeutically even after THA, since arthrogenic muscle inhibition commonly occurs in muscles surrounding peripheral joints after surgical intervention (Mumbleau et al., 2020).

The identification of weak strength components in hip, knee and ankle muscles may improve cycling performance and reduce the risk of injury (So et al., 2005). Handheld dynamometers provide a quantified measurement of force when performing manual muscle testing and have been advocated as an alternative to the isokinetic assessment since they are portable devices, less expensive, requires a shorter measurement time, easier use and impose a less cost burden for researchers and patients (Kim et al., 2014; Martins et al., 2017). We used the HHD with beltstabilization as external fixation to 
minimize limitations of the assessment such as individual's tester muscle strength (K. Thorborg et al., 2010b; Kristian Thorborg et al., 2013). Even if this strength assessment is not considered the gold standard, it allows to measure and detect deficits and asymmetries in athletes with more precision than manual muscle testing.

Our study has limitations, such as the fact that it is a case study, which restricts its application to other populations. It was not possible to follow physical training before surgery or any rehabilitation protocol performed so that such information comes from the patient's selfreport, which is subject to memory bias. The influence of mild $\mathrm{OA}$ of the contralateral limb on the variables analyzed was also not evaluated.

Considering that ergometer cycling is recommended in the early postoperative phase of THA in elderly (di Monaco \& Castiglioni, 2013; Liebs et al., 2010), further studies should investigate if earlier return to cycling in athletes after THA or hip arthroscopy are safe and improve muscle strength imbalances and quality of life.

\section{Practical Applications.}

1. Casartelli, N. C., Maffiuletti, N. A., ItemGlatthorn, J. F., Staehli, S., Bizzini, M., Impellizzeri, F. M., \& Leunig, M. (2011). Hip muscle weakness in patients with symptomatic femoroacetabular impingement. Osteoarthritis and Cartilage, 19(7), 816821.

https://doi.org/10.1016/j.joca.2011.04.0 01

2. di Monaco, M., \& Castiglioni, C. (2013). Which type of exercise therapy is effective after hip arthroplasty? A systematic review of randomized controlled trials. European Journal of Physical and Rehabilitation Medicine, 49(6), 893-907, quiz 921-923. http://www.ncbi.nlm.nih.gov/pubmed /24172644
In the present study, we observed the gradual resumption of amateur cycling after THA for the treatment of severe osteoarthritis due to FAI. Our results demonstrated the permanence of some residual deficits in adductor and flexor hip strength at 24 months after THA. This suggests that such muscle groups should be monitored in rehabilitation programs.

In the present case, no other factor was considered harmful to the maintenance and progression of training and gradual improvement of sports performance.

\section{Conclusions}

Despite the slight deficits in strength observed at the end of the 24 months after surgery when compared to the preoperative evaluation, no other factor can be considered harmful to the maintenance and progression of sports performance. Which demonstrates good responsiveness to surgical treatment in the present case report.

Funding: This research received no external funding.

Conflicts of Interest: The authors declare no conflict of interest.

\section{References}

3. Diamond, L. E., Dobson, F. L., Bennell, K. L., Wrigley, T. v, Hodges, P. W., \& Hinman, R. S. (2015). Physical impairments and activity limitations in people with femoroacetabular impingement: a systematic review. British Journal of Sports Medicine, 49(4), 230-242.

https://doi.org/10.1136/bjsports-2013093340

4. Dingemans, S. A., Kleipool, S. C., Mulders, M. A. M., Winkelhagen, J., Schep, N. W. L., Goslings, J. C., \& Schepers, T. (2017). Normative data for the lower extremity functional scale (LEFS). Acta Orthopaedica, 88(4), 422-426. https://doi.org/10.1080/17453674.2017. 1309886 
5. Frank, R. M., Ukwuani, G., Clapp, I., Chahla, J., \& Nho, S. J. (2018). High Rate of Return to Cycling After Hip Arthroscopy for Femoroacetabular Impingement Syndrome. Sports Health: A Multidisciplinary Approach, 10(3), 259-265.

https://doi.org/10.1177/1941738117747 851

6. Friesenbichler, B., Casartelli, N. C., Wellauer, V., Item-Glatthorn, J. F., Ferguson, S. J., Leunig, M., \& Maffiuletti, N. A. (2017). Explosive and maximal strength before and 6 months after total hip arthroplasty. Journal of Orthopaedic Research. https://doi.org/10.1002/jor.23626

7. Greene, B. R., Odonovan, A., RomeroOrtuno, R., Cogan, L., Scanaill, C. N., \& Kenny, R. A. (2010). Quantitative falls risk assessment using the timed up and go test. IEEE Transactions on Biomedical Engineering, 57(12), 2918-2926. https://doi.org/10.1109/TBME.2010.208 3659

8. Griffin, D. R., Dickenson, E. J., O'Donnell, J., Agricola, R., Awan, T., Beck, M., Clohisy, J. C., Dijkstra, H. P., Falvey, E., Gimpel, M., Hinman, R. S., Hölmich, P., Kassarjian, A., Martin, H. D., Martin, R., Mather, R. C., Philippon, M. J., Reiman, M. P., Takla, A., ... Bennell, K. L. (2016). The Warwick Agreement on femoroacetabular impingement syndrome (FAI syndrome): An international consensus statement. British Journal of Sports Medicine, 50(19), 1169-1176.

https://doi.org/10.1136/bjsports-2016096743

9. Jones, C. A., \& Pohar, S. (2012). HealthRelated Quality of Life After Total Joint Arthroplasty. A Scoping Review. In Clinics in Geriatric Medicine (Vol. 28, Issue 3, pp. 395-429). W.B. Saunders. https://doi.org/10.1016/j.cger.2012.06.0 01

10. Kim, W. K., Kim, D. K., Seo, K. M., \& Kang, S. H. (2014). Reliability and validity of isometric knee extensor strength test with hand-held dynamometer depending on its fixation: A pilot study. Annals of Rehabilitation Medicine, 38(1), 84-93. https://doi.org/10.5535/arm.2014.38.1.8 4

11. Lai, A. K. M., Dick, T. J. M., Brown, N. A. T., Biewener, A. A., \& Wakeling, J. M. (2020). Lower-limb muscle function is influenced by changing mechanical demands in cycling. The Journal of Experimental Biology, 224( $\mathrm{Pt} 3)$. https://doi.org/10.1242/jeb.228221

12. Liebs, T. R., Herzberg, W., Rüther, W., Haasters, J., Russlies, M., \& Hassenpflug, J. (2010). Ergometer cycling after hip or knee replacement surgery: A randomized controlled trial. Journal of Bone and Joint Surgery Series A, 92(4), 814-822. https://doi.org/10.2106/JBJS.H.01359

13. Loureiro, A., Constantinou, M., Diamond, L. E., Beck, B., \& Barrett, R. (2018). Individuals with mild-tomoderate hip osteoarthritis have lower limb muscle strength and volume deficits. BMC Musculoskeletal Disorders, 19(1). https://doi.org/10.1186/s12891018-2230-4

14. Loureiro, A., Mills, P. M., \& Barrett, R. S. (2013). Muscle weakness in hip osteoarthritis: a systematic review. In Arthritis care $\mathcal{E}$ research (Vol. 65, Issue 3, pp. 340-352). Arthritis Care Res (Hoboken). https://doi.org/10.1002/acr.21806

15. Martin, J. C., \& Brown, N. A. T. (2009). Joint-specific power production and fatigue during maximal cycling. Journal of Biomechanics, 42(4), 474-479. https://doi.org/10.1016/j.jbiomech.2008 .11 .015

16. Martin, J. C., \& Nichols, J. A. (2018). Simulated work loops predict maximal human cycling power. Journal of Experimental Biology, 221(13). https://doi.org/10.1242/jeb.180109

17. Martins, J., da Silva, J. R., da Silva, M. R. B., \& Bevilaqua-Grossi, D. (2017). Reliability and validity of the beltstabilized handheld dynamometer in hip-and knee-strength tests. Journal of 
Athletic Training, 52(9), 809-819. https://doi.org/10.4085/1062-605052.6 .04

18. Mehta, S. P., Fulton, A., Quach, C., Thistle, M., Toledo, C., \& Evans, N. A. (2016). Measurement Properties of the Lower Extremity Functional Scale: A Systematic Review. Journal of Orthopaedic and Sports Physical Therapy, 46(3), 200-216. https://doi.org/10.2519/jospt.2016.6165

19. Montin, L., Suominen, T., Haaranen, E., Katajisto, J., Lepistö, J., \& Leino-Kilpi, H. (2011). The changes in healthrelated quality of life and related factors during the process of total hip arthroplasty. International Journal of Nursing Practice, 17(1), 19-26. https://doi.org/10.1111/j.1440172X.2010.01901.x

20. Mumbleau, A. M., Schilaty, N. D., \& Hewett, T. E. (2020). HIP MUSCLE INHIBITION AFTER HIP ARTHROSCOPY: A ROLE FOR NEUROMUSCULAR ELECTRICAL STIMULATION. International Journal of Sports Physical Therapy, 15(6), 12221228.

https://doi.org/10.26603/ijspt20201222

21. Perrin, D. H. (1993). Terminology and the isokinetic torque curve. In Isokinetic exercise and assesment (pp. 13-20). Human Kinetics Publishers.

22. Quintana, J. M., Escobar, A., Bilbao, A., Arostegui, I., Lafuente, I., \& Vidaurreta, I. (2005). Responsiveness and clinically important differences for the WOMAC and SF-36 after hip joint replacement. Osteoarthritis and Cartilage, 13(12), 1076-1083. https://doi.org/10.1016/j.joca.2005.06.0 12

23. Raasch, C. C., \& Zajac, F. E. (1999). Locomotor strategy for pedaling: Muscle groups and biomechanical functions. Journal of Neurophysiology, 82(2), $515-525$. https://doi.org/10.1152/jn.1999.82.2.515 24. Ryan, M. M., \& Gregor, R. J. (1992). EMG profiles of lower extremity muscles during cycling at constant workload and cadence. Journal of Electromyography and Kinesiology, 2(2), 69-80. https://doi.org/10.1016/10506411(92)90018-E

25. So, R. C. H., Ng, J. K.-F., \& Ng, G. Y. F. (2005). Muscle recruitment pattern in cycling: a review. Physical Therapy in Sport, $6(2)$. https://doi.org/10.1016/j.ptsp.2005.02.0 04

26. Thorborg, K., Petersen, J., Magnusson, S. P., \& Hölmich, P. (2010a). Clinical assessment of hip strength using a hand-held dynamometer is reliable. Scandinavian Journal of Medicine and Science in Sports, 20(3), 493-501. https://doi.org/10.1111/j.16000838.2009.00958.x

27. Thorborg, K., Petersen, J., Magnusson, S. P., \& Hölmich, P. (2010b). Clinical assessment of hip strength using a hand-held dynamometer is reliable. Scandinavian Journal of Medicine and Science in Sports, 20(3), 493-501. https://doi.org/10.1111/j.16000838.2009.00958.x

28. Thorborg, Kristian, Bandholm, T., \& Hölmich, P. (2013). Hip- and kneestrength assessments using a handheld dynamometer with external beltfixation are inter-tester reliable. Knee Surgery, Sports Traumatology, Arthroscopy.

https://doi.org/10.1007/s00167-0122115-2

29. Williams, D. H., Greidanus, N. v., Masri, B. A., Duncan, C. P., \& Garbuz, D. S. (2012). Predictors of participation in sports after hip and knee arthroplasty. Clinical Orthopaedics and Related Research, 470(2), 555-561. https://doi.org/10.1007/s11999-0112198-y

30. Winther, S. B., Foss, O. A., Husby, O. S., Wik, T. S., Klaksvik, J., \& Husby, V. S. (2019). Muscular strength and function after total hip arthroplasty performed with three different surgical approaches: one-year follow-up study. HIP International, 29(4), 405-411. 
https://doi.org/10.1177/1120700018810 673

31. Yuksel, E., Unver, B., Kalkan, S., \& Karatosun, V. (2021). Reliability and minimal detectable change of the 2minute walk test and Timed Up and Go test in patients with total hip arthroplasty. HIP International, 31(1), 43-49. https://doi.org/10.1177/1120700019888

614

Zacharias, A., Pizzari, T., English, D. J., Kapakoulakis, T., \& Green, R. A. (2016). Hip abductor muscle volume in hip osteoarthritis and matched controls. Osteoarthritis and Cartilage, 24(10), 1727-1735. https://doi.org/10.1016/j.joca.201 6.05 .002 